\title{
Probiotic Effect of Lebanese Darfiyeh Cheese: A Randomized Case Control Prospective Study in the Elderly
}

\author{
Toufic Saber1, Jihad Irani2,3, Claude Afif ${ }^{2,3}$, Nazem Bassil ${ }^{2,3}$, Elie Estephan ${ }^{2,3}$, \\ Mireille Serhan', Marcel Bassil1,4* \\ ${ }^{1}$ Faculty of Health Sciences, University of Balamand, Beirut, Lebanon \\ ${ }^{2}$ Faculty of Medicine, University of Balamand, Beirut, Lebanon \\ ${ }^{3}$ Saint George Hospital-University Medical Center, Beirut, Lebanon \\ ${ }^{4}$ Biotechnology Department, Benta Pharma Industries, Dbayeh, Lebanon \\ Email: ${ }^{*}$ marcel.bassil@bpi.com.lb
}

Received 12 July 2015; accepted 4 September 2015; published 7 September 2015

Copyright @ 2015 by authors and Scientific Research Publishing Inc.

This work is licensed under the Creative Commons Attribution International License (CC BY).

http://creativecommons.org/licenses/by/4.0/

(c) (i) Open Access

\begin{abstract}
A randomized case control prospective method was adopted in this study in order to assess the health benefit associated with the Darfiyeh cheese, a traditional Lebanese raw goat milk cheese ripened in goat skin. 21 participants were recruited and divided into 2 groups: test group $(n=10)$ and control group $(n=11)$. Venous blood and stools were collected at day 14, 21 and day 0 and 21 respectively. Flow cytometry was performed on blood sample. Fecal samples were plated on Plate Count Agar (PCA) and de Man, Rogosa and Sharpe Agar (MRS) agar in order to monitor any alteration in the gastrointestinal tract (GIT). At day 24, a significant increase by $27.67 \%(p=0.043)$ in the bacterial count was seen on the MRS agar for the test group in comparison to no change in the total bacterial count. At day 14 a significant drop $(p=0.026)$ in $C D 3+/ C D 4+$ population in the test group (35.67 vs 42.87$)$, and a non-significant drop $(p=0.818)$ in CD8+ $(24.76$ vs 28.28$)$ is seen when compared to control group. At day 24 , no significant change $(p=0.20)$ in the CD3+/CD4+ population in comparison between both groups and no change in CD8+ or Geo means in both groups. In conclusion, an alteration in the GIT microflora could be hinted at by the lactobacilli bacterium, which was not reflected on the total bacterial count.
\end{abstract}

\section{Keywords}

Lactococcus lactis Subsp. Lactis, Lactobacillus plantarum, Darfiyeh Cheese, Probiotic Effect, Elderly

\footnotetext{
${ }^{*}$ Corresponding author.
}

How to cite this paper: Saber, T., Irani, J., Afif, C., Bassil, N., Estephan, E., Serhan, M. and Bassil, M. (2015) Probiotic Effect of Lebanese Darfiyeh Cheese: A Randomized Case Control Prospective Study in the Elderly. Food and Nutrition Sciences, 6, 1086-1094. http://dx.doi.org/10.4236/fns.2015.612113 


\section{Introduction}

The Food and Agriculture Organization (FAO) and the World Health Organization (WHO) working group described that probiotics must have live microorganisms and that they should confer a measured physiological health benefit, as well as possessing well-being effects in the human host [1]. Probiotics are widely used as food additives because they have the ability of fermentation, which can affect the taste of food [2]-[4]. In addition, many probiotic strains such as Lactic Acid Bacteria (LAB) are used in studies as vaccine vehicles, as microbial interference treatments or as adjuvant for antibiotics [1].

LAB are physiologically present in the human digestive tract [5]. They have evolved symbiotically with the digestive tract [1] [6]. These bacterial strains are able to ferment nutriments into lactic acid or other byproducts [1] [5] [6]. LAB also have the ability to lower the $\mathrm{pH}$ in the GIT and female genital tract, which is a healthy and beneficial phenomenon since low $\mathrm{pH}$ implement an antibacterial effect [7] [8].

Raw goat milk, which is best known for its indigenous microflora is highly linked to probiotic effects in the human body [9]. The microflora mostly consisting of LAB allows this specific type of milk to have beneficial and valuable health impact on the consumer. Raw goat milk has served for many decades in the manufacturing of Darfiyeh, a cheese ripened in goat skin [10]. A highly developed and diverse ecosystem is found in this cheese: bacteria, molds and yeasts [11]. The bacteria present in this cheese are Streptococcus thermophilus, Enterococcus feacium, Enterococcus feacalis, Lactobacillus plantarum, Staphylococcus haemolyticus, Escherichia coli and Clostridium spp.

It has been shown that Lactococcuslactis subsp. lactis does not possess any invasive capacity, thus it has shown no bacterial translocation after the admission of 109 CFU of viable Lactococcuslactis subsp. lactis in human at the mesenteric lymph node sites [6].

Lactobacillus plantarum does not possess any infective capacity and is not able to cross the intestinal barrier, and therefore does not have the capacity to cause bacteremia [6] [12] [13]. In addition, Lactobacillus plantarum has been shown to possess an antibacterial activity as resultant of secretion of bacteriocins against common pathogens [14]. Moreover, this bacterium has the ability to enhance the systematic immunity by increasing the number of B lymphocytes, natural killer cells and the activation of CD4+ and CD8+ cells [15] [16]. In accordance to the FAO and the WHO guidelines, probiotic organisms, which are used in food, must have the ability to stay alive in the gastric juices and they should be resistant to the exposure to the bile in the human gut. In addition, they must have the ability to flourish and colonize the digestive tract of humans [17].

Among the possible mechanisms of probiotic therapy is promotion of a nonimmunologic gut defense barrier, which includes the normalization of increased intestinal permeability and altered gut microflora. Another possible mechanism of probiotic therapy is improvement of the intestine's immunologic barrier [18]. LAB have been shown to enhance the proliferation of Th and Treg cells. More specifically, Lactobacillusplantarum enhances the proliferation of CD3 and CD4, which are markers for Th and Treg cells [19] [20]. Few studies assessing the potential health benefit of each of the two-bacterium Lactocuccuslactis sub species lactis and lactobacillus plantarum have been done [16] [21]. No study was done combining both bacteria and testing their effects on human health. To evaluate the role of the two-bacterium, a randomized case control prospective method was adopted in the study in order to assess their health benefit associated with the intake of Darfiyeh in Lebanese elderly.

\section{Methods}

\subsection{Darfiyeh Cheese Samples}

Experimental cheeses were processed at small cheese scale farming in North Lebanon Mountains, and ripened in goatskins [10]. After 21 days of ripening, the goatskin was opened through the neck. Representative cheeses were selected randomly and taken out for microbiological analyses. Fractions of whole cheese samples (20 g interior and surface) were homogenized in $180 \mathrm{~mL}$ of sterile $2 \%(\mathrm{w} / \mathrm{v})$ tri-sodium citrate dehydrate solution serially diluted $\left(10^{-1}-10^{-7}\right)$ in a sterile physiological solution and plated onto different media (Salmonella-Shigella Agar (SS), MacConkey Agar, and Mannitol Salt Agar (MSA)). The absence of growth on the aforementioned media reflects in order the absence of Salmonella ssp, Shigella ssp, potential pathogenic gram-negative bacteria, and Staphylococcus. 


\subsection{Subjects and Trial Design}

This trial was conducted, in winter 2013, in subjects older than 64, institutionalized in the Foyer Saint George in Beirut, where they benefit from a pre-planned diet and a twenty-four hours medical supervision. Exclusion criteria were 1) suffering from lactose intolerance, 2) suffering from metastatic cancer, 3) documented intolerance to milk or dairy products, 3) use of antibiotics, or nutritional supplements in the previous month, 4) intake of any dairy product (yoghurt, etc.) all over the trial period and 5) BMI $<16$.

21 elderly subjects were randomized. Subjects were divided into 2 groups based on their randomized number (odd number formed the test group $(\mathrm{n}=9)$, even number formed the control group $(\mathrm{n}=12)$ ).

The test group was given $20 \mathrm{~g}$ of cheese as described by Mane et al. [21]. The cheese was administered every 2 days all over the period of 24 days. The study design is shown in Figure 1.

The Body Mass Index (BMI) of each participant was calculated in order the monitor his diet status, which was used as an external variable. A stool culture (dependent method) was also performed in order to monitor the basal colonies forming units (CFU) of each of the two studied strains in the feces of each participant. MRS and plate count agars are used.

\subsection{Flow Cytometry}

The flow cytometry technique was adopted to quantify the components of the cellular immunity. The following lymphocytes were quantified: Th, Tc and Treg, using specific markers (Table 1). The flow cytometry methodology was performed using two different protocols: one for extra cellular markers (CD3, CD4, CD8, CD19) and a second one for intracellular markers (FoxP3) [22].

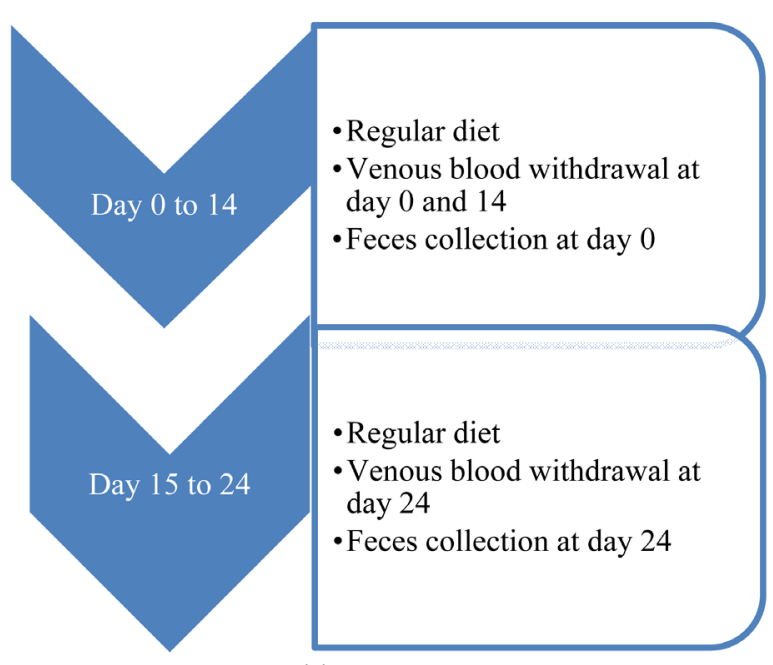

(a)

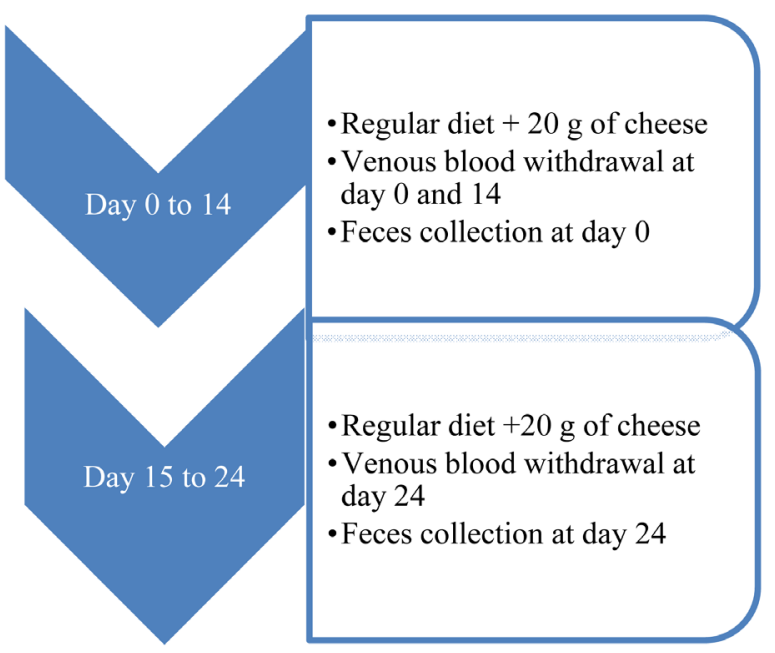

(b)

Figure 1. Study design scheme for control $(a)(n=12)$ and test $(b)(n=9)$ groups, during the course of the trial 9 out of 21 participants left the trial. 5 out of 9 left the test group.

Table 1. Association between Th, Tc, Treg cells with their CD markers.

\begin{tabular}{cccc}
\hline Marker & Th & Tc & + \\
CD3 & + & - & Treg \\
CD4 & + & + & + \\
CD8 & - & - \\
CD25 & - & - \\
FoxP3 (intracellular) & - & + \\
+
\end{tabular}




\subsection{Bacterial Count}

Samples of feces $(20 \mathrm{mg}$ ) were collected and put under sterile conditions in $10 \mathrm{~mL}$ of Bactotryptone. A series of dilution was performed and $1 \mathrm{~mL}$ of each dilution was plated on LAB plate count agar and MRS agar. The plates were kept for 3 days at 30 degree Celsius. Colonies were counted and the results were plotted in parallel for each group.

\subsection{Ethical Considerations}

This study was given the approval of the Institutional Review Board (IRB) and the Ethical Committee of the University of Balamand and the Saint George Hospital University Medical Center. All subjects gave their informed consent to participate in the study.

\subsection{Statistical Analysis}

Simple descriptive statistics to describe our studied population was used. Means, standard deviations and medians were used for quantitative data; proportions were used for qualitative data. Mann-Whitney test was used for comparison among the two groups when appropriate; Wilcoxon signed ranked test was also used for the analysis when it was appropriate. All statistical analyses were performed using the SPSS software for windows. p values below 0.05 were considered as significant.

\section{Results}

At day 0 and 24, the sample age of the participants was carefully calculated and double checked on their medical file. The average age of the test group is 86 years while the average age of the control group is 85 years. Using the medical records of the participants their gender was identified. $35 \%$ of the participants are male and $65 \%$ are female (data not shown). In addition to their age and gender the weight and height of each participants was also checked in the medical record. The BMI of each participants was carefully calculated using the following formula: weight $(\mathrm{kg}) /$ height $\wedge 2\left(\mathrm{~m}^{\wedge} 2\right)$. Any participant with a BMI less than 16 was excluded from the study at day 0 . The average BMI of all the participants at days 0 and 24 is shown in Table 2.

Vomiting, constipation and diarrhea were also monitored before, during and at the end of the trial (data not shown). These data were used to evaluate any physiological effects, which affect the bowel. Data were collected at days 0 and 24. These data refer to any episode of diarrhea or vomiting during a period of 5 days before the date of the data collection. The results show that 5 out of 12 participants showed constipation during and at the end of the trial. 2 out of those 5 belong to the test group. Regarding diarrhea, 1 out of the 12 participants showed to have more than one episode of diarrhea during the past week from the data collection date. This participant belongs to the control group. One participant showed to have one episode of vomiting during the past week from the data collection date. The latter belongs to the control group.

Bacterial count was done on MRS and PCA agars at days 0 and 24. The number of stool samples collected at days 0 and 24, was 14 and 11 samples respectively. The CFU count was made by applying the following formula: $50 \times 20(\mathrm{mg}) \times 10^{\wedge}$ number of dilution. The mean CFU for the MRS agar showed $356 \times 10^{\wedge} 6$ and $371 \times$ $10^{\wedge} 6$ for days 0 and 24 for the control group. The mean CFU for the MRS agar showed $112 \times 10^{\wedge} 6$ and $143 \times$ $10^{\wedge} 6$ for days 0 and 24 for the test group. The mean CFU for the PCA agar showed $1444 \times 10^{\wedge} 6$ and $1530 \times$ $10^{\wedge} 6$ for days 0 and 24 for the control group. The mean CFU for the PCA agar showed $4075 \times 10^{\wedge} 6$ and $4231 \times$ $10^{\wedge} 6$ for days 0 and 24 for the test group (Table 2).

Different dyes were used in order to quantify the CDs marker. Results are shown in Figure 2. The statistical interpretation of the CD3+/CD4+ population of cells, the CD8+ cells and the CD3+/CD4+ X and Y Geo mean of both groups is shown in Table 3 .

Table 2. BMI distribution and bacterial count (expressed in CFU $\times 10^{6}$ ) for control test and control groups at days 0 and 24 .

\begin{tabular}{ccccc}
\hline & Test group & \multicolumn{2}{c}{ Control group } & \multicolumn{2}{c}{ Day 0 } & Day 24 \\
\cline { 2 - 5 } & Day 0 & Day 24 & 26.3 & 26.8 \\
Average BMI & 25.3 & 26.05 & 1444 & 1530 \\
CFU $^{*}\left(\times 10^{6}\right)$-PCA & 4075 & 4231 & 143 & 356 \\
CFU $\left(\times 10^{6}\right)$-MRS agar & 112 & 371 \\
\hline
\end{tabular}


Table 3. Flow cytometry data (mean \pm standard deviation) at days $14 \%$ and 24\% and \% change between days 14 and 24 .

\begin{tabular}{cccc}
\hline & Mean \pm SD at day 14 & Mean \pm SD at day 24 & $\begin{array}{c}\text { \% change between } \\
\text { days } 14 \text { and } 24\end{array}$ \\
\hline Control group CD3/CD4 & $42.87 \pm 7.67$ & $36.08 \pm 10.10$ & -8.60 \\
Control group Others CD3 & $22.01 \pm 12.17$ & $32.77 \pm 3.96$ & 19.64 \\
Test group CD3/CD4 & $35.67 \pm 3.61$ & $44.07 \pm 4.73$ & 10.53 \\
Test group Others CD3 & $30.14 \pm 11.10$ & $25.38 \pm 12.05$ & -8.57 \\
Control group CD8 & $28.28 \pm 6.04$ & $30.14 \pm 4.75$ & 3.18 \\
Test group CD8 & $24.76 \pm 8.70$ & $28.31 \pm 10.32$ & 6.69 \\
Control group CD3/CD4 X Geo & $21.11 \pm 0.21$ & $31.45 \pm 1.28$ & 19.67 \\
Control group CD3/CD4 Y Geo & $427.37 \pm 33.51$ & $438.75 \pm 87.32$ & 1.31 \\
Test group CD3/CD4 X Geo & $20.17 \pm 1.73$ & $29.73 \pm 3.40$ & 19.16 \\
Test group CD3/CD4 Y Geo & $418.2 \pm 43.94$ & $434.45 \pm 45.26$ & 1.91 \\
Control group CD8 Y Geo & $63.03 \pm 5.78$ & $65.59 \pm 3.05$ & 1.99 \\
Test group CD8 Y Geo & $59.5 \pm 3.22$ & $63.36 \pm 2.16$ & 3.14 \\
\hline
\end{tabular}

Note a mean of CD3+/CD4+ of 42.87 and 36.08 at day 14 and 24 for the control group. The mean of CD3+/CD4+ showed 35.67 and 44.07 at day 14 and 24 for the test group. The mean of CD8+ showed 32.71 and 28.35 at day 14 and 24 for the test group. The mean of CD8+ showed 31.96 and 30.14 at day 14 and 24 for the control group. CD3/CD4 X and Y Geo means were also noted.

\section{Discussion}

It has been documented that probiotic strains are able to upkeep a healthy digestive system and functioning [23]. The Darfiyeh cheese contained two well-documented probiotic strains: Lactococcus lactis subsp. lactis and Lactobacillus plantarum [5] [24]. Participants were under dairy product-free diet. The latter was used to control and avoid overlapping in the results. This overlapping might be due to the fact that dairy products can contain the two bacteria of interest. This overlapping could also result from orange juice, corn flakes and chocolate [24]. These products were never been administered to the participants.

Darfiyeh cheese contains a high concentration of salt (up to $0.5 \mathrm{M}$ ), and therefore has a salty taste. This fact had raised the burden of an increased blood pressure. Therefore, the weight of the cheese was accurately monitored to ensure that only 20 grams were administered. The blood pressure was checked regularly. No sign of increase in the blood pressure was noted. No side effects related to the administration of the cheese were observed during the trial period. The percentage of participants with diarrhea at day 24 remained the same in comparison with day 0 in both groups (data not shown). The percentage of constipation and vomiting was also constant in between day 0 and day 24 in both groups. No change more than 5\% was noted in the BMI of each participant (Table 2).

The data showed in Table 2 suggests a 4.21\% increase in the bacterial count for the control group on MRS agar. This count increased dramatically by $27.67 \%$ for the test group on the MRS agar considered to be statistically significant. This difference suggests a baseline increase of the lactobacilli found in the stools for the test group who consumed the Darfiyeh during the past 24 days. This difference is not observed in the control group. On PCA agar 5.95\% ( $=0.177)$ and 3.82\% ( $=0.2)$ are the level of increase shown on this agar for the control and test group respectively. This increase cannot be considered of significant interest and could not indicate any change in the total count of aerobes in the microflora of the GIT. These counts could suggest that the total count for bacteria in both groups was not affected but the specific count of lactobacilli shows a difference between the two groups [24] [25]. This could be explained by the fact that the lactobacilli found in the cheese was able to reach the GIT and alter the microflora of the GIT of the participants in the test group [5] [18]. Moreover, Lactococcus lactis subsp. lactis was identified on PCA without being selective for the Lactococcus lactis subsp lactis [3]. This has created a burden in analyzing the effect of the cheese on the microflora of the GIT [17] [18]. 

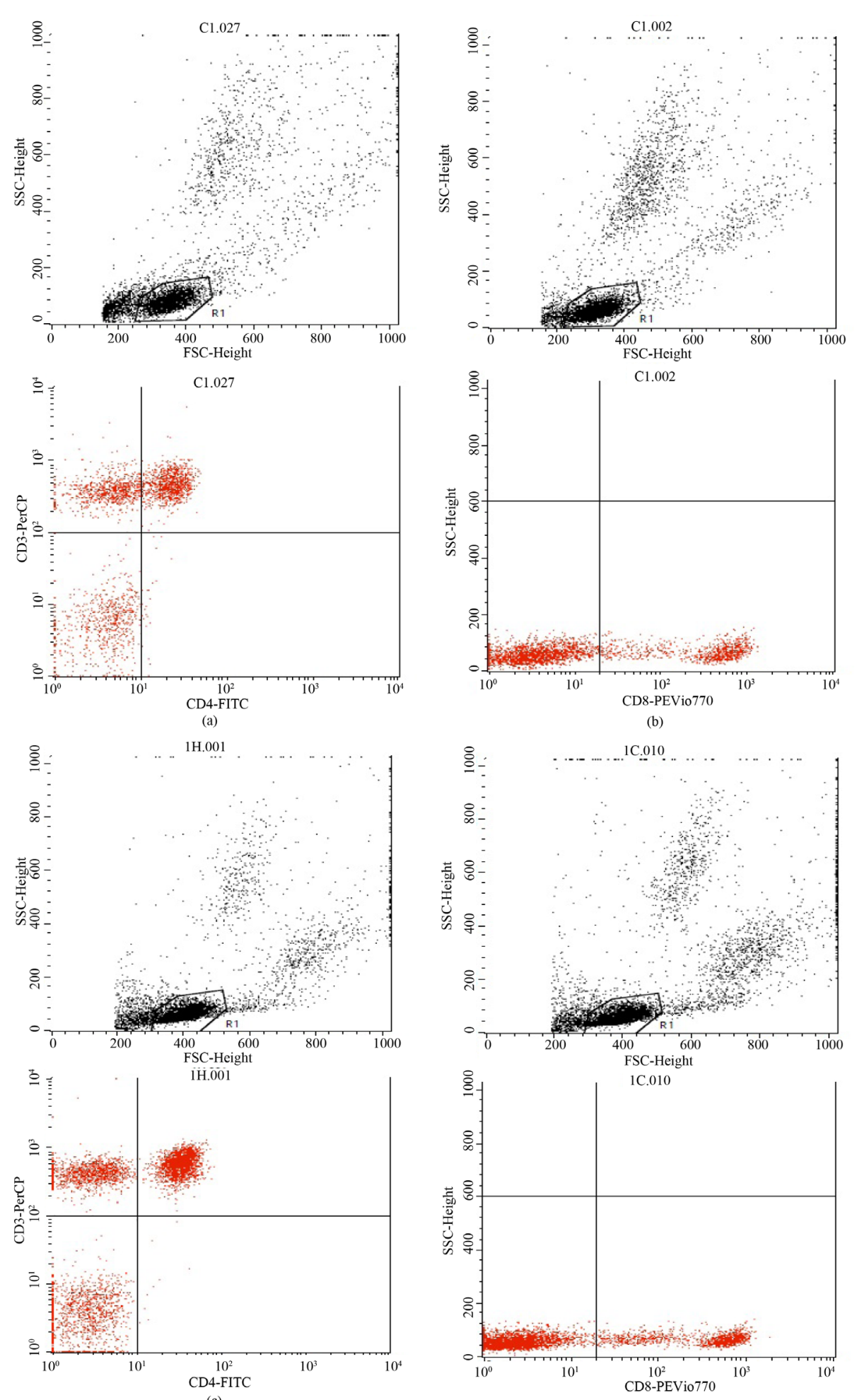

(c)

(d)

Figure 2. (a) Lymphocyte gate for CD3+/CD4+ cells at day 14: \%CD3+ cells are located in the upper left (UL) and upper right (UR) quadrants. \%CD4+ cells are located in the UR quadrant; (b) Lymphocyte gate for \%CD8+ cells at day 14. \%CD8+ cells are located in the lower right (LR) quadrant; (c) Lymphocyte gate for CD3+/CD4+ cells at day 24. \%CD3+ cells are located in the upper left (UL) and upper right (UR) quadrants. \%CD4+ cells are located in the UR quadrant; (d) Lymphocyte gate for \%CD8+ cells at day 24. \%CD8+ cells are located in the lower right (LR) quadrant. 
In general, inflammation and immunity modifications are critical to advance nearly every complex condition in the human body, thus the need to use "tools" which are able to modulate immunity either by up regulating or by down regulating the immune response [23]. Lactobacillus plantarum and Lactococcus lactis subsp lactis are good "tools", classified as probiotics, able to create immunomodulation in the GIT. This fact has been shown in this study by a decrease in CD3+/CD4+ population in the test group in comparison to the control group. This decrease is considered to be statistically significant at day $14(\mathrm{p}=0.026)$. The drop in CD8+ is not statistically significant $(\mathrm{p}=0.818)$. Regarding the Geo Means they were statistically not significant; drop in all test groups at day $14(\mathrm{p}=0.009)$. However, when added all together, it looks like the test group show a significant decrease in Th cells and its level of CD3+ and CD4+, and no significant change was noted regarding the CD8+ cells expression. This could be attributed to a stimulation of the Th cells leading to a cellular response which did not involve the lymphocyte $\mathrm{T}$ cytotoxic and could have involve other type of immunity which was not quantified in this study [26]-[28].

At day 24, there is an increase in the CD3+/CD4+ population $(\mathrm{p}=0.2)$ in the test group in comparison to the control group (44.07 vs 36.08). No change in CD8+ or Geo means of all (p-values of 0.8181 and 1 respectively). This could be explained by a potential investment of the cells stimulated up to day 14 [28] [29]. This stimulation could have been invested in the stimulation of a humoral immunity, which was not quantified in this study. This humoral immunity could involve the production of interleukin (IL 1-IL10) and the secretion of immunoglobulin (IgG, IgM, IgA) [28] [30]. In other studies, Lactobacillus plantarum and Lactococcus lactis subsp lactis were able to stimulate the cellular and humoral immunity. This has been observed in this study by a down regulation then an up-regulation of the Th cells. In addition, a drop by $8.6 \%(\mathrm{p}=0.029)$ is seen in the population of CD3+/CD4+ reflecting a drop in the Th cells in the control between day 14 and day 24 . A $10.53 \%$ increase in the population of Th cells for the test group was noted $(p=0.029)$. This up regulation could suggest a sensitization of the Th cells created by the intake of the Darfiyeh cheese. Regarding the Tc cells, a modest up regulation for the test group is seen in comparison with the control group, suggesting the absence or modest effect on the intake of the cheese on the sensitization process of these cells. An over sensitization of the Th cells could aggravate Th-mediated autoimmune disease such as rheumatoid arthritis. Thus there is a need to quantify the cellular immunity and the production of Il1 and Il10 in future studies [28]. Note that to attribute the down and up regulation in the population of CD3+/CD4+ cells to the Lactobacillus plantarum and Lactococcus lactis subsp lactis solely is not accurate. Thus the need to identify the potential molecules which could be responsible of this stimulation and use them in an in vitro context (cell culture) with non-sensitize lymphocyte (naïve lymphocytes). This sensitization has to be monitored in order to identify a potential sensitization and lymphocytes proliferation which could happen after the stimulation with the potential molecules.

The results suggest that the ratio of the two bacterial strains present in the cheese could modulate an alteration in microflora of the GIT. However this is not enough to play a role in boosting the immune system of elderly people as stated in previous studies [3] [5] [24] [25]. This finding could be linked to the consumption of the Darfiyeh during the trial period leading to the conclusion that the bacterial strains were able to cross and pass all over the GIT [23].

\section{Conclusion}

Our study was able to investigate an up and down regulation of Th cells which could be related to the probiotic effect of the two bacterial strains. In addition, during the course of the study, we were able to observe an alteration in the microflora of the GIT but no changes were observed regarding the total bacterial count in the feces. This study has set the basics and the standards for future studies. These basics could be summarized by the baseline, which is created by the consumption of the normal Darfiyeh; in addition to the optimization of the methodology used in order to generate results. The small sample size was a limitation in this study. Note that dealing with elderly people was a real advantage and problem at the same time. The advantage was obvious in the quantification of results and making the subject follow the strict diet. The problem was illustrated by their difficult behavior and mis judgment on daily facts which could affect others opinion. A prospective study dealing with elderly people having different immune reactions is recommended to be made on larger scale, among different age groups of Lebanese elderly.

\section{Acknowledgements}

The authors a knowledge and thank the Foyer Saint George in Beirut for data collection. 


\section{Funding}

The study was funded by the University of Balamand.

\section{References}

[1] Savijoki, K., Ingmer, H. and Varmanen, P. (2006) Proteolytic Systems of Lactic Acid Bacteria. Applied Microbiology and Biotechnology, 71, 394-406. http://dx.doi.org/10.1007/s00253-006-0427-1

[2] Casalta, E. and Montel, M.C. (2008) Safety Assessment of Dairy Microorganisms: The Lactococcus genus. International Journal of Food Microbiology, 126, 271-273. http://dx.doi.org/10.1016/j.ijfoodmicro.2007.08.013

[3] Koretz, R.L. (2009) Probiotics, Critical illness, and Methodologic Bias. Nutrition in Clinical Practice, 24, 45-49. http://dx.doi.org/10.1177/0884533608329296

[4] Han, W., Mercenier, A., Ait-Belgnaoui, A., Pavan, S., Lamine, F., van Swarm, I.I., et al. (2006) Improvement of an Experimental Colitis in Rats by Lactic Acid Bacteria Producing Superoxide Dismutase. Inflammatory Bowel Disease, 12, 1044-1052. http://dx.doi.org/10.1097/01.mib.0000235101.09231.9e

[5] Kaushik, J.K., Kumar, A., Duary, R.K., Mohanty, A.K., Grover, S. and Batish, V.K. (2009) Functional and Probiotic Attributes of an Indigenous Isolate of Lactobacillus plantarum. PLoS One, 4, 8099. http://dx.doi.org/10.1371/journal.pone.0008099

[6] Pavan, S., Desreumaux, P. and Mercenier, A. (2003) Use of Mouse Models to Evaluate the Persistence, Safety, and Immune Modulation Capacities of Lactic Acid Bacteria. Clinical and Diagnostic Laboratory Immunology, 10, 696-701. http://dx.doi.org/10.1128/cdli.10.4.696-701.2003

[7] Bremner, A.R. and Beattie, R.M. (2002) Therapy of Crohn's Disease in Childhood. Expert Opinion in Pharmacotherapy, 3, 809-825. http://dx.doi.org/10.1517/14656566.3.7.809

[8] Pillai, A. and Nelson, R. (2008) Probiotics for Treatment of Clostridium difficile-Associated Colitis in Adults. Cochrane Database of Systematic Reviews, 1, Article ID: CD004611. http://dx.doi.org/10.1002/14651858.CD004611.pub2

[9] Hirose, Y., Murosaki, S., Yamamoto, Y., Yoshikai, Y. and Tsuru, T. (2006) Daily Intake of Heat-Killed Lactobacillus plantarum L-137 Augments Acquired Immunity in Healthy Adults. Journal of Nutrition, 136, 3069-3073.

[10] Serhan, M., Linder, M., Hosri, C. and Fanni, J. (2010) Changes in Proteolysis and Volatile Fraction during Ripening of Darfiyeh, a Lebanese Artisanal Raw Goat's Milk Cheese. Small Ruminant Research, 90, 75-82. http://dx.doi.org/10.1016/j.smallrumres.2010.01.008

[11] Serhan, M., Cailliez-Grimal, C., Borges, F., Revol-Junelles, A.M., Hosri, C. and Fanni, J. (2009) Bacterial Diversity of Darfiyeh, a Lebanese Artisanal Raw Goat’s Milk Cheese. Food Microbiology, 26, 645-652. http://dx.doi.org/10.1016/j.fm.2009.04.012

[12] Garde, S., Avila, M., Arias, R., Gaya, P. and Nunez, M. (2011) Outgrowth Inhibition of Clostridium beijerinckii Spores by a Bacteriocin-Producing Lactic Culture in Ovine Milk Cheese. International Journal of Food Microbiology, 150, 59-65. http://dx.doi.org/10.1016/j.ijfoodmicro.2011.07.018

[13] Adawi, D., Molin, G., Ahrne, S. and Jeppson, B. (2002) Safety of the Probiotics Strain Lactobacillus plantarum DSM 9843 (=Strain 299v) in an Endocarditis Animal Model. Microbial Ecology in Health and Disease, 14, 50-53. http://dx.doi.org/10.1080/089106002760002766

[14] Niedzielin, K., Kordecki, H. and Birkenfeld, B. (2001) A Controlled, Double-Blind, Randomized Study on the Efficacy of Lactobacillus plantarum 299V in Patients with Irritable Bowel Syndrome. European Journal of Gastroenterology and Hepatology, 13, 1143-1147. http://dx.doi.org/10.1097/00042737-200110000-00004

[15] Kimoto, H., Nomura, M., Kobayashi, M., Mizumachi, K. and Okamoto, T. (2003) Survival of Lactococci during Passage through Mouse Digestive Tract. Canadian Journal of Microbiology, 49, 707-711. http://dx.doi.org/10.1139/w03-092

[16] Dal Bello, B., Cocolin, L., Zeppa, G., Field, D., Cotter, P.D. and Hill, C. (2012) Technological Characterization of Bacterio Cin Producing Lactococcus lactis Strains Employed to Control Listeria monocytogenes in Cottage Cheese. International Journal of Food Microbiology, 153, 58-65. http://dx.doi.org/10.1016/j.ijfoodmicro.2011.10.016

[17] Aggarwal, J., Swami, G. and Kumar, M. (2013) Probiotics and Their Effects on Metabolic Diseases: An Update. Journal of Clinical and Diagnostic Research, 7, 173-177. http://dx.doi.org/10.7860/jcdr/2012/5004.2701

[18] Dicks, L.M. and Botes, M. (2010) Probiotic Lactic Acid Bacteria in the Gastro-Intestinal Tract: Health Benefits, Safety and Mode of Action. Beneficial Microbes, 1, 11-29. http://dx.doi.org/10.3920/BM2009.0012

[19] De Vries, M.C., Vaughanb, E.E., Kleerebezema, M. and De Vosa, W.M. (2006) Lactobacillus plantarum-Survival, Functional and Potential Probiotics Properties in the Human Intestinal Tract. International Dairy Journal, 16, 10181028. http://dx.doi.org/10.1016/j.idairyj.2005.09.003 
[20] Ogier, J.C. and Serror, P. (2008) Safety Assessment of Dairy Microorganisms: The Enterococcus Genus. International Journal of Food Microbiology, 126, 291-301. http://dx.doi.org/10.1016/j.ijfoodmicro.2007.08.017

[21] Mane, J., Pedrosa, E., Loren, V., Gassull, M.A., Espadaler, J., Cune, J., et al. (2011) A Mixture of Lactobacillus plantarum CECT 7315 and CECT 7316 Enhances Systemic Immunity in Elderly Subjects: A Dose-Response, Double-Blind, Placebo-Controlled, Randomized Pilot Trial. Nutricion Hospitalaria, 26, 228-235.

[22] Chow, S., Hedley, D., Grom, P., Magari, R., Jacobberger, J.W. and Shankey, T.V. (2005) Whole Blood Fixation and Permeabilization Protocol with Red Blood Cell Lysis for Flow Cytometry of Intracellular Phosphorylated Epitopes in Leukocyte Subpopulations. Cytometry A, 67, 4-17. http://dx.doi.org/10.1002/cyto.a.20167

[23] Borchers, A.T., Selmi, C., Meyers, F.J., Keen, C.L. and Gershwin, M.E. (2009) Probiotics and Immunity. Journal of Gastroenterology, 44, 26-46. http://dx.doi.org/10.1007/s00535-008-2296-0

[24] Isolauri, E., Sutas, Y., Kankaanpaa, P., Arvilommi, H. and Salminen, S. (2001) Probiotics: Effects on Immunity. American Journal of Clinical Nutrition, 73, 444S-450S.

[25] Rizzello, V., Bonaccorsi, I., Dongarra, M.L., Fink, L.N. and Ferlazzo, G. (2011) Role of Natural Killer and Dendritic Cell Crosstalk in Immunomodulation by Commensal Bacteria Probiotics. Journal of Biomedicine and Biotechnology, 2011, Article ID: 473097. http://dx.doi.org/10.1155/2011/473097

[26] Michetti, P., Dorta, G., Wiesel, P.H., Brassart, D., Verdu, E., Herranz, M., et al. (1999) Effect of Whey-Based Culture Supernatant of Lactobacillus acidophilus (johnsonii) La1 on Helicobacter pylori Infection in Humans. Digestion, 60, 203-209. http://dx.doi.org/10.1159/000007660

[27] Baharav, E., Mor, F., Halpern, M. and Weinberger, A. (2004) Lactobacillus GG Bacteria Ameliorate Arthritis in Lewis Rats. Journal of Nutrition, 123, 1964-1969.

[28] Kato, I., Endo-Tanaka, K. and Yokokura, T. (1998) Suppressive Effects of the Oral Administration of Lactobacillus casei on Type II Collagen-Induced Arthritis in DBA/1 Mice. Life Sciences, 63, 635-644. http://dx.doi.org/10.1016/S0024-3205(98)00315-4

[29] Ratajczak, C., Duez, C., Grangette, C., Pochard, P., Tonnel, A.B. and Pestel, J. (2007) Impact of Lactic Acid Bacteria on Dendritic Cells from Allergic Patients in an Experimental Model of Intestinal Epithelium. Journal of Biomedicine and Biotechnology, 2007, Article ID: 71921. http://dx.doi.org/10.1155/2007/71921

[30] Taylor, A.L., Dunstan, J.A. and Prescott, S.L. (2007) Probiotic Supplementation for the First 6 Months of Life Fails to Reduce the Risk of Atopic Dermatitis and Increases the Risk of Allergen Sensitization in High-Risk Children: A Randomized Controlled Trial. Journal of Allergy and Clinical Immunology, 119, 184-191. http://dx.doi.org/10.1016/j.jaci.2006.08.036 